\title{
Non-timber forest products in community development: Lessons from the Russian Far East
}

\author{
by Nikolay Shmatkov ${ }^{1}$ and Tim Brigham ${ }^{2}$
}

\begin{abstract}
One of the components of the IUCN - The World Conservation Union project, "Building Partnerships for Forest Conservation and Management in Russia" funded by the Canadian International Development Agency (CIDA), is designed to assist remote communities of the Russian Far East to sustainably develop their NTFP resources. In our project, NTFPs are viewed as one part of a local sustainable livelihood strategy (including tourism, cultural activities, hunting, herding). We provide business and legal issues training, consultation on small business and community-based enterprise development, and support for sustainability and monitoring programs. One of the basic principles of the project has been a participatory approach to project development and implementation. It is the hope of project participants that the successful development of NTFP and other opportunities will decrease the pressure to move forward with potentially damaging resource exploitation activities. Although community economic development is the primary goal, the revival and sharing of indigenous knowledge about NTFPs has been identified by participants as a key issue, and is a focus of educational materials being developed through the project.
\end{abstract}

Key words: non-timber forest products (NTFPs), community economic development, sustainable use of natural resources, Native communities, traditional knowledge, the Russian Far East, Kamchatka, Sakhalin, boreal forests, IUCN - The World Conservation Union, Canadian International Development Agency (CIDA)

L'une des composantes du projet de conservation mondiale de l'UICN, «Établir des partenariats pour la conservation et l'aménagement des forêts de la Russie » financée par l'Agence canadienne de développement international, a été conçue pour aider les communautés isolées de l'Extrême -Orient russe à développer de façon durable leurs produits forestiers non ligneux (PFNL). Dans notre projet, les PFNL sont considérés comme un élément de la stratégie liée au mode de vie locale (comprenant le tourisme, les activités culturelles, la chasse et le pâturage des troupeaux). Nous apportons une formation liée aux questions d'administration et de législation, la consultation pour le développement de petites entreprises et d'entreprises reposant sur la communauté et des appuis pour les programmes portant sur la durabilité et le suivi. L'un des principes de base du projet a porté sur l'approche participative pour le développement et l'implantation du projet. Les participants au projet souhaitent que le développement réussi des PFNL et d'autres opportunités permettent de diminuer la pression exercée pour aller de l'avant avec des activités d'exploitation des ressources potentiellement destructrices. Même si le développement économique communautaire demeure le principal objectif, la renaissance et le partage des connaissances locales sur les PFNL ont été identifiés par les participants comme un enjeu déterminant, et sont au centre du matériel éducatif en cours d'élaboration par l'entremise du projet.

Mots-clés: produits forestiers non ligneux (PFNL), développement économique communautaire, utilisation durable des ressources naturelles, communautés autochtones, connaissances traditionnelles, Extrême-Orient russe, Kamchatka, Sakhalin, forêts boréales, Union internationale de conservation de la nature - UICN, Agence canadienne de développement international (ACDI)

\section{Introduction}

For anyone who has spent time in remote northern communities in either Canada or Russia, similarities in the interests, concerns, and realities of local people in both countries can be striking. For many Indigenous communities in northern Canada and northern Russia, under- and unemployment, poverty, cultural dislocation, and a creeping sense of hopelessness have become commonplace. Large-scale industrial development has benefited some residents of the North, but most locals, and especially Indigenous people, are stuck on the outside looking in.

Russia's boreal forest is of global importance because of its size, carbon-storage capacity, biodiversity, and wide range of forest (timber and non-timber) products. It is equally important nationally for its contribution to the economy in terms of the gross domestic product, export earnings, and employment, as well as for its vital role in the material and spiritual

${ }^{1}$ NTFP Component Co-ordinator, IUCN - The World Conservation Union Office for Russia and CIS, Moscow, Russia, 17 Marshal Vasilevski St., 123182 Moscow Russia. E-mail: shmatkov@iucn.ru

${ }^{2}$ NTFP Business Development Consultant, 3878 Cowichan Lake Rd., Duncan, BC V9L 6K1. E-mail: tbrigham @islandnet.com cultures of Indigenous peoples. Despite vast resources and the global demand for forest products, the Russian forest sector has been experiencing severe management problems that threaten socio-economic stability and the ecological integrity of the forests. The legacy of centralized planning polices, the recent transition to a market economy and ensuing economic and political turmoil have all diminished the country's capacity to effectively manage its forest resources. These issues are severe impediments to the conservation and sustainable development of Russia's forests, and they urgently need to be addressed. Addressing these issues is a major focus of the IUCN Temperate and Boreal Forest Program (IUCN-Canada) and Forest Conservation Program (IUCN-Russia/CIS).

Over the past year and a half, we have been involved with a community economic development project focused on the Kamchatka Peninsula and Sakhalin Island in the Russian Far East. Our project is actually one component of the larger project "Building Partnerships for Forest Conservation and Management in Russia" funded by the Canadian International Development Agency (CIDA) and managed by IUCN - The World Conservation Union. Our project on "Building Community Capacity for Sustainable Non-Timber Forest Products Harvesting, Monitoring, 


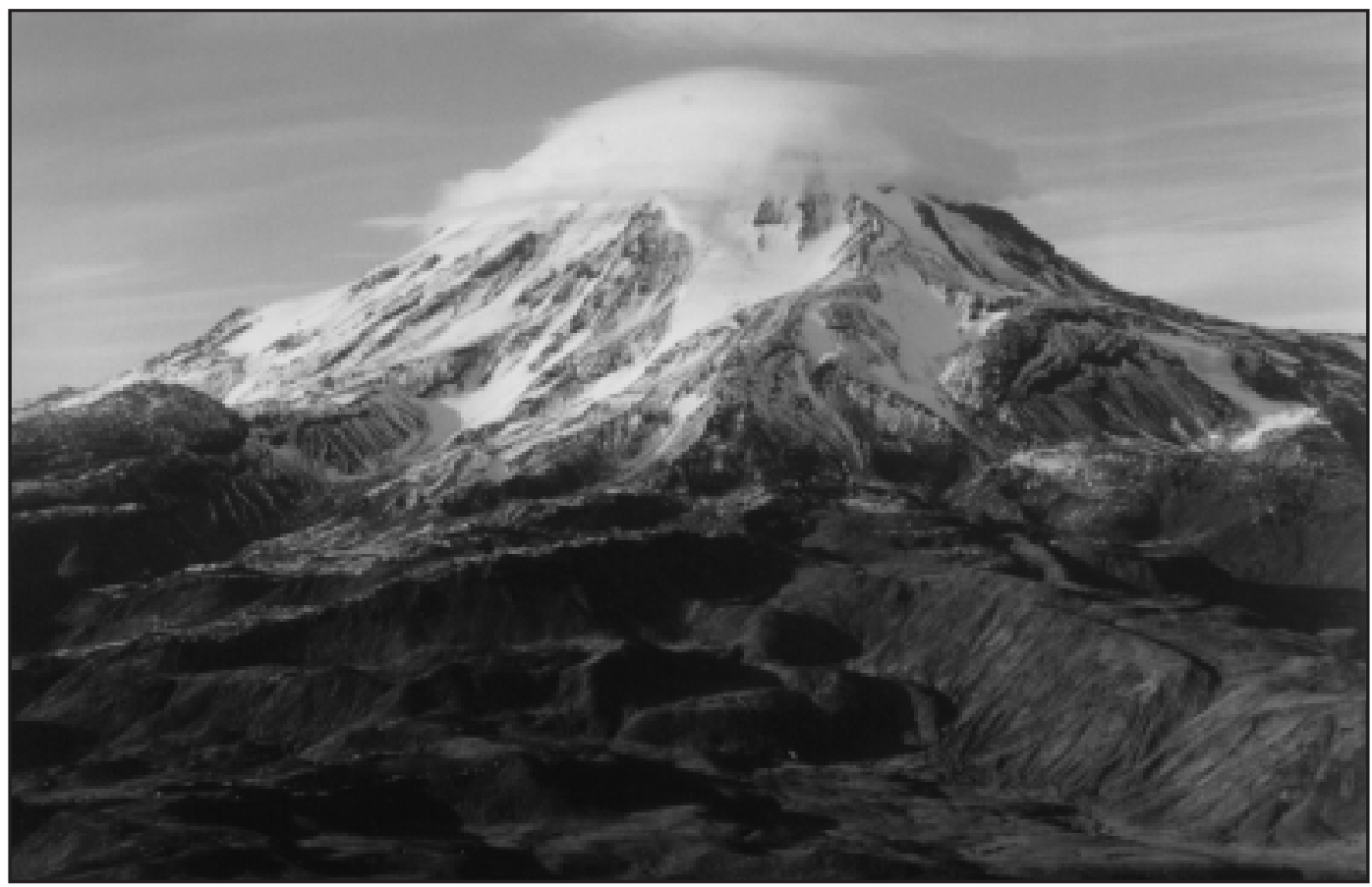

and Marketing on Kamchatka and Sakhalin" is aimed at assisting remote communities of the Russian Far East to sustainably develop their non-timber forest product resources. Non-timber forest products (NTFPs) are any plant or fungi resources of the forest other than timber, pulpwood, or firewood. Examples of NTFPs include berries, mushrooms, and herbal medicines; although actual "products" vary from place to place, NTFPs are used around the world by all cultures.

\section{Kamchatka: Land of Fire and Ice}

With 29 active volcanoes, some reaching over 4000 metres in height, and the largest surviving populations of wild salmon and brown bear, Kamchatka has a richly deserved reputation as a wild and relatively untouched land of "fire and ice." In spite of, or perhaps because of, its remoteness, Bystrinski Nature Park, a World Heritage Site since 1996, is becoming increasingly popular among Russian and international tourists. Bystrinski is unique among the protected areas of Kamchatka, with more than 2500 people living within its boundaries, many of them representatives of Indigenous peoples of small nations-including the Eveni, Itelmen, Koriak, and Chukcha—struggling for their survival. Some Indigenous people continue to follow their traditional way of life in the forests and tundra of the park and surrounding territory. Communities living on the territory of the park are an important factor influencing the management of natural resources, including NTFPs.

Apart from the difficulties presented by living in a remote area with a harsh environment, many of Kamchatka's residents are facing new challenges brought on by the collapse of the Soviet regime. Since the early 1990s, communities on Kamchatka (and elsewhere in the country) have experienced economic decline made worse by the withdrawal of federal support to outlying regions and traditional resource use such as reindeer herding. Some residents who lost their traditional sources of income have been forced to turn to poaching in the park creating additional pressure on biodiversity, especially on populations of salmon and large mammals. The situation has been further com- plicated by the lack of any legal basis for the management of park resources. Attempts to put into practice mechanisms to ensure the sustainable use of resources have been negatively viewed by local people as a strategy to prevent communities from benefiting from the natural resources of the park.

Seeking a solution to the economic woes facing the region, members of the local and regional administrations of Kamchatka are looking to exploit mineral resources in this ecologically sensitive area. Of course, it is unrealistic to compare the economic returns from gold mining in Bystrinski District to the potential value of developing NTFPs on the same territory. On the other hand, the question must be asked: who will benefit from mining development? There is a real risk that the industrial development of natural resources will provide few or no economic benefits to local communities while further damaging their ability to pursue traditional and new livelihood activities including NTFP business development, eco-tourism, reindeer herding, and wild salmon harvesting. Local salmon stocks - essential to the subsistence economy and culture of Native Peoples-are at particular risk from the technologies for gold extraction proposed for the area. Now, as was the case in 1996 when IUCN led the campaign against gold mining in Bystrinski Nature Park, the issue of industrial development is once again acute in this part of Kamchatka. As a nature conservation organization, it is essential for IUCN to provide effective tools to local Native communities to enable them to increase incomes through the sustainable use of resources.

\section{Focusing on Local Needs: A Participatory Approach}

One of the basic principles of the project has been a participatory approach to project development and implementation. This allows for more pragmatic decisions based on local experience, but also gives the community a stake in the project. The project team (including local co-ordinators) has worked hard to ensure that the interests and vision of local peo- 
ple are included in project design and implementation. The team is especially proud that the participatory approach led to cultural issues being given more attention in the project. Although community economic development is the primary goal, the revival and sharing of indigenous knowledge about NTFPs — especially for younger people — has been identified by participants as a key concern, and is a focus of educational materials being developed through the project. The recent publication on traditional use of dwarf Siberian pine, as well as project support for a workshop on sustainable birch bark harvesting and weaving (videotaped for further distribution by our local partners), exemplify the educational dimension of the project.

The project is focusing on groups who have previously had few opportunities to participate in small business or natural resource management-Indigenous people and women. It is the intention of all involved that over time, local community groups (perhaps organized along the lines of a co-op, or "community enterprise" as they're known on Kamchatka) will take over all the production and marketing activities involved in organizing and running a NTFP-based business. However, with no or limited experience in the marketplace, project participants-mainly Indigenous women - are vulnerable to exploitation by "big business" interests from outside the area. Our role is to provide business support services to ensure enterprises are established and the participants have a clear understanding of sound business practices.

\section{The First Year and a Half: Overcoming Scepticism and Building Capacity}

The project has faced many challenges in its first year and a half of working "on the ground." Getting local communities to buy into the project has not always been easy. At times, local residents found planting potatoes and harvesting berries in the forest preferable to sitting through a workshop on legal issues. One of the biggest challenges has been the scepticism of local residents and authorities to the idea of community economic development in general, and to economically viable and sustainable NTFP-based business development in particular. The predominant viewpoint was that harvesting in large volumes and selling as raw materials is the only worthwhile approach to marketing NTFPs. This "commodity approach" to NTFP development faces many barriers in the form of low prices and the high costs involved in reaching markets from Kamchatka. A shortage of information about the industry and a lack of business skills also prevent many people from setting up their own business. On top of these other challenges, a complex tangle of poorly developed legislation on small business development as well as sizeable direct and indirect tax barriers also have a suffocating effect on entrepreneurial activity. In this environment, training, communication, and long-term mentoring and support to emerging businesses is a vital role for our project.

From our perspective, over-coming scepticism and enhancing the likelihood that the project will have long-term, positive impacts requires a more participatory — and patient—approach to working through issues. For example, in Year 2, a common feature of workshops we have run with participants and communities new to the project is something we dubbed "scepticism analysis." Essentially, this exercise provides an opportunity to "get out in the open" all the doubts and questions participants have about the project and its goals. These questions might range from "Why would Canada want to help us?" to "How can we

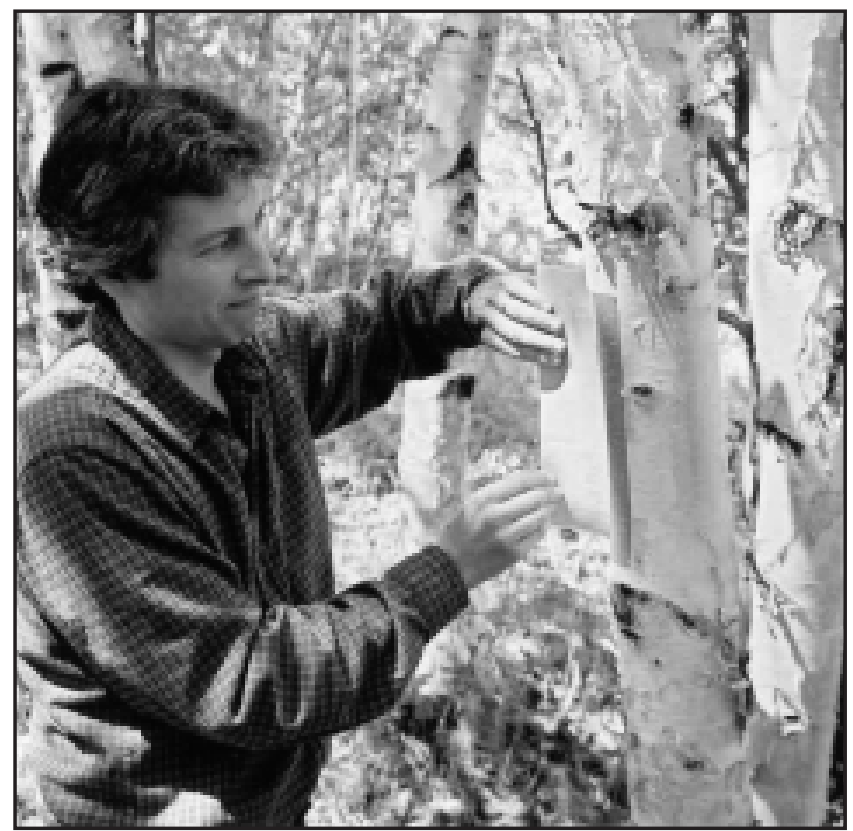

sell something when we're so far from a good market?" Most of the questions we have encountered in communities are extremely reasonable; left unaddressed, they could have a very detrimental impact on project participation.

Addressing the wide range of issues that hinder NTFP business development requires action on many fronts, as well as new and flexible approaches to dealing with challenges. Furthermore, the unique characteristics of Kamchatka present the project with additional questions quite apart from the issues and challenges common to most community economic development projects. What follows is an overview of some of the key activities in the project's first two years.

\section{A park with people}

The lack of a management plan for Bystrinski Nature Park or effective forum for the discussion of park resources has also stood in the way of achieving the goal of sustainable park management. With two villages within its boundaries, Bystrinski's future depends on its effective management for both biodiversity benefits and the benefit of local people. Many locals have been deeply suspicious of the process of park "development" because of fears - certainly supported by evidence from other jurisdictions - that local people would inevitably lose out.

It was clear early on that the "park question" would be an important factor in the work of the project. Our ability to push for the development of a park management plan through a consultative process has its limits, but we have had success in influencing the process. To help create a forum for productive dialogue between stakeholders in the sustainable co-management of the resources of the park, the project supported the establishment of the Bystrinski Information Centre with the staff of the park administration and community members. In its first few months of operation, the Centre has developed as an important facility for community development workshops, collection of traditional knowledge, community-based sustainability research programmes, and local NTFP festivals. We hope it will also serve to bring different members of the community together in shaping the future of Bystrinski Nature Park. 


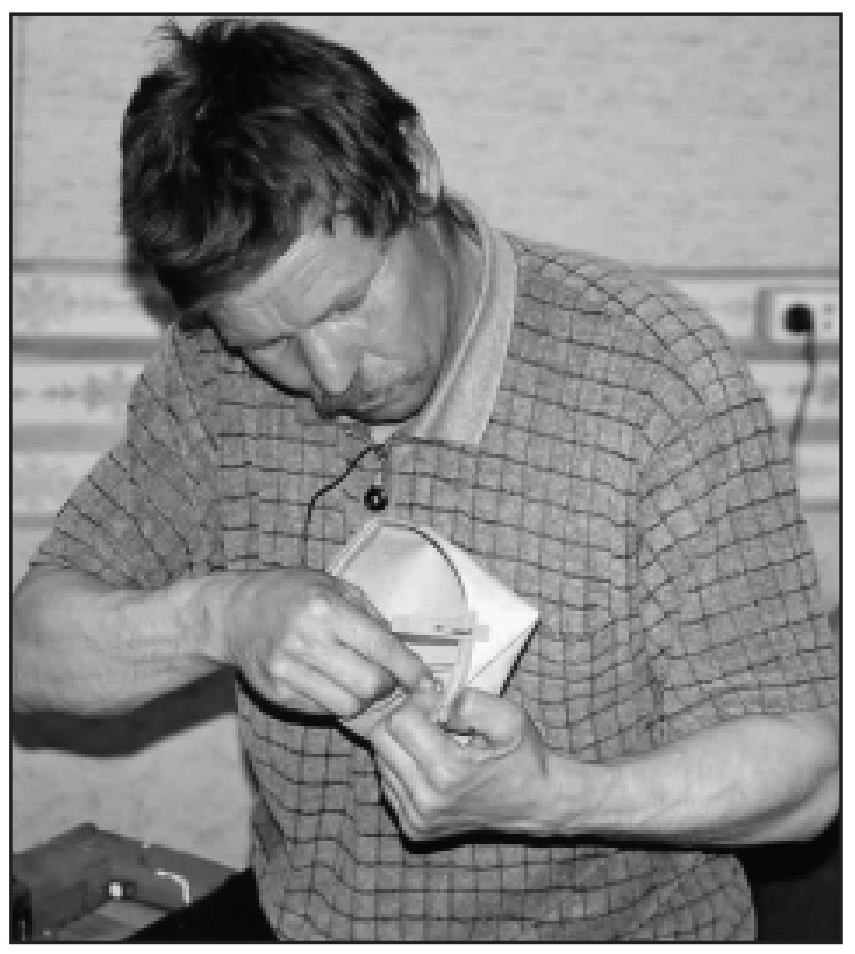

Volcanoes, toxins, and community health

As one of the most active parts of the Pacific "Ring of Fire," Kamchatka continues to be shaped by forces from deep within the earth's crust. Along with gold, other mineral resources are abundant on the Peninsula, including platinum, copper, and a wide range of rare and heavy metals. Volcanic activity brings many of these elements to the surface, creating a potential threat to the health of local people. Heavy and rare metals that occur naturally in the soil and water of specific sites on Kamchatka pose a potential risk to those in the local population - such as Native People - who consume large amounts of wild-harvested fish, meat, and plants. A concern of the project is that NTFPs growing in some locations may not be safe to consume in large quantities over a long period of time.

One of the objectives of the project is to help local people avoid sites contaminated by naturally occurring toxins when harvesting NTFPs for their own consumption or for commercial purposes. The research-led by Elena Dulchenko, an expert with the Pacific Institute of Geography (Kamchatka Branch, the Far Eastern Branch of the Russian Academy of Science)forms the basis for recommendations on specific plant species and parts of plants that are safe to harvest from certain locations near the villages. Ms. Dulchenko's research has already had an impact on the harvesting regime for certain species of NTFPs.

\section{Products with potential: tea and bark}

Working closely with our community partners, and taking into account the specific ecological, social, and economic conditions of Kamchatka, the project team has selected products with good potential for commercial development. One of these products, herbal teas, has an extensive history with the Indigenous peoples in the area, with many recipes handed down through the generations. In August 2001, the project helped organize a contest on herbal teas with our partner communities, which was timed to coincide with a local festival. The contest was a huge success with over 400 people voting on their favourite teas and over 1500 people witnessing the "awards celebration". The contest provided valuable feedback to the tea producers, and generated a number of recipes for producing samples that we provided to buyers outside Russia. An unforeseen outcome of the contest was the role it played in convincing a number of project participants that consumers truly are interested in these products. Residents of the communities have also produced samples of unique and attractive packaging for the teas made from sustainably harvested birch bark and small-diameter wood. A major aim of product development within the project is to produce higher value, recognizably "Kamchatkan" products wherever possible, in order to maximize economic benefits to local communities.

The day of the Herbal Tea Festival became the start date for the community movement now known as the "Kamchatka Herbal Tea Club." Begun mostly as an educational and social organization, the Club has transformed into a community-based co-operative, in which several Indigenous women and their families are working on the sustainable harvest and marketing of wild-harvested herbal teas. Ms. Vera Gurkina, one of the leaders of the local Eveni Nation community, is the head of this business. Over the course of her involvement in the project, she has grown increasingly excited by the opportunities presented by the NTFP industry. She has also faced many challenges in developing the business side of the organization. Errors in planning the harvesting of tea ingredients, and a lack of responsibility on the part of some of her business partners, created a number of problems in meeting the first order from Canada. With the help of the project, she is confident she will overcome these problems for the next production season.

The search for unique packaging for the herbal teas led us to another NTFP product that has already proven its market potential: birch bark crafts. True masters of the art of birch bark weaving, Nikolay and Ludmilla Shishkin produce a wide range of crafts, from simple baskets to beautifully woven boxes. The Shishkins have also proven to be excellent and passionate teachers, willingly sharing their weaving secrets during a five-day workshop sponsored by the project in June 2002. During the workshop, emphasis was placed on using sustainable harvesting methods that would ensure tree survival. Nikolay was able to show an example of a healthy tree that had been "harvested" 30 years previously, with only a slightly discoloured band of bark indicating where the original bark had been removed.

Apart from its potential as packaging for other products (Kamchatka Herbal Tea utilizes a "Shishkin design" in its birch bark packaging), birch bark can also be used to produce crafts with a high demand in the market place. Foreign buyers in Canada and the US have already expressed great interest in the Shishkins' creations. On the recently completed Canadian study tour (see below), Nikolay sold all the craft samples he brought with him, and without question, could have sold many more. With a product clearly in great demand, the Shishkins will be increasing their production in the coming year, while continuing to work with others interested in learning the art of sustainable craft production for their own enjoyment or as a source of additional income.

With a nod to the importance of diversification, and a wish to provide as many opportunities as possible for participating 


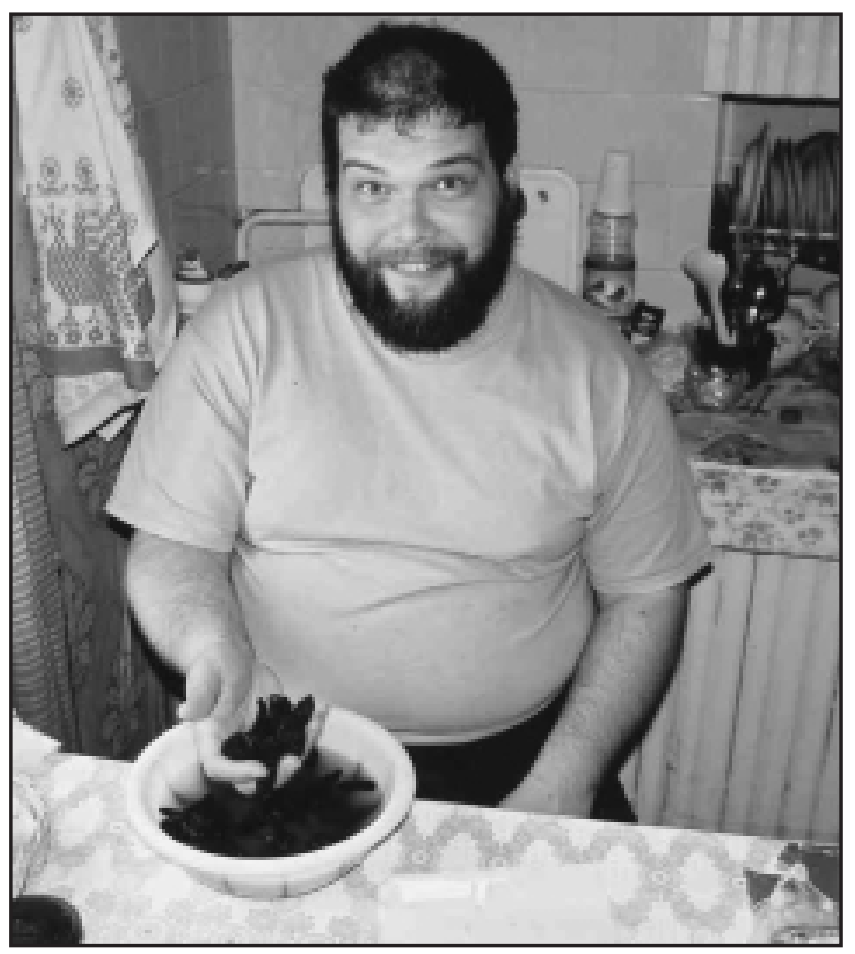

communities to generate economic benefits from NTFPs, the project continues to work on new products for development. Dried berries and mushrooms, dried wild onions, syrups, and medicinal herbs are all being explored for their market potential.

\section{Monitoring impacts}

As the world's largest conservation organization, IUCN is especially sensitive to the issue of sustainability. We are working closely with communities participating in the project to ensure none of the wild species utilized in product development are vulnerable to over-harvesting or are threatened in any way. To assess the impacts of NTFP development, we have established a pilot community-based monitoring program for Bystrinski Nature Park. The goal of the program is to examine the impacts of various harvesting methods on plants such as brusnika (Vaccinium vitis-idaea), an important NTFP in Bystrinski District. For the pilot, research sites were chosen with the assistance of the community based on traditional brusnika berry harvesting areas. Our aim is to determine if harvesting berries with the use of rakes and picking leaves for herbal teas could influence the production of berries and leaves in following years, and if so, how? The Bystrinski Park Director and a Native community leader were field-trained in establishing sample plots, using different methods of harvesting, and in performing basic mapping of the sample plot. The actual research was conducted with the help of members of a local tourist and environmental club for youth-at-risk. By establishing long-term monitoring over a number of plots, we hope to compare the influence of various harvesting methods on the NTFP resource base over time. We believe the results will assist local communities and the Nature Park Administration to choose sustainable methods and levels of harvesting and, in the long run, help to find a proper balance between the two major objectives of Bystrinski Nature Park-biodiversity preservation and support for the traditional culture and way of life of Native residents.

\section{Learning from each other: the Canadian NTFP study tour}

A major goal of the project, as well as Canadian aid to Russia in general, is building cultural and business bridges between the two countries. A further project goal is to develop and introduce new models for community economic development appropriate to the Russian Far East context based on the sustainable use of NTFPs. To help achieve these goals, several Indigenous entrepreneurs, NGO leaders, community members, and a representative of the United Nations Development Program project on Kamchatka were selected to participate in a study tour to Canada that took place in October 2002. Although different criteria were used in selecting participants for the tour, all shared the important attribute of an ability and willingness to disseminate the knowledge gained during the tour upon returning to Russia.

During the tour to Manitoba and British Columbia, the group met with some twenty organizations and visited five Indigenous communities to share experiences related to NTFP business development. Tour participants benefited from the opportunity to observe practical, functioning models of NTFP small business development in the two provinces they visited. In British Columbia, the tour visited with participants in the North Island NTFP Demonstration Project, an applied research project employing a multi-faceted approach to dealing with the complex question of how best to manage non-timber forest products for environmental, economic, and social benefits. Through the use of resource inventories, applied research, new management models, capacity-building, and business development assistance for local entrepreneurs, the North Island Project is seeking to create a model for NTFP development that can be successfully applied throughout the province and eventually in other jurisdictions as well.

A memorable part of the tour for participants was a visit to the Northern Forest Diversification Centre (NFDC), a subsidiary of Keewatin Community College in The Pas, Manitoba. As with the Russian project, the NFDC is utilizing NTFPs as a tool in community economic development, targeting a similar client group: mainly Aboriginal, often in remote communities, with high levels of under- and unemployment, and facing a host of other social challenges. Against this backdrop, the two projectsone in Russia and one in Canada_-are employing remarkably similar approaches in seeking to address the problems faced by remote communities. Both projects provide community-based training, support to new entrepreneurs, and product research and development for the NTFP industry. As is the case with the IUCN-CIDA project, the NFDC puts sustainability at the forefront of its mission. Both projects base their activities on the sustainable use of local products and environments in a way that is compatible with the skills, knowledge, and aspirations of local residents. The projects also share the goal of maximizing the benefits of local resources for local people. Increased local-level processing, careful selection of products for development, and help in creating direct connections between community entrepreneurs and more lucrative markets are just a few examples of how benefits can be maximized at the local level.

With their shared objectives, and similar approaches to achieving them, it was logical for the IUCN project and the NFDC to look for opportunities for co-operation. Co-operation was envisaged as not only benefiting the two organizations, but more importantly, benefiting the communities served by these two 
projects. It also provides the chance for both organizations to learn from each other about new NTFPs from a shared environment - the vast circumpolar boreal forest region of both countries - as well as learn about opportunities to do "new things" with better-known products. For example, "fruit leather," a popular snack in North America, appears to be virtually unknown in Russia. The NFDC is currently researching recipes and techniques for producing wild berry fruit leathers that could be applicable to the Russian Far East with its vast berry resources. In return, the NFDC has a desire to learn about NTFPs from Russia such as wild mushroom seasoning, birch sap, birch bark crafts, and others.

Study tour participants were very interested in the NFDC model and how it functioned in supporting NTFP (and another NFDC priority, ecotourism) businesses in Indigenous communities in Manitoba. The visitors from Kamchatka and Sakhalin spent many hours becoming acquainted with equipment in the NFDC workshop, doing a number of hands-on exercises and producing their own crafts from driftwood and twigs. "It's unfortunate we can't load the NFDC onto a helicopter and carry it to Kamchatka," said Vera Gurkina. Although the helicopter did not materialize, participants and NFDC staff did discuss opportunities for further developing the partnership to support sustainable NTFP- and ecotourism-based businesses in the Russian Far East.

Without question, the knowledge gained and the new contacts made will assist participants in establishing and promoting economically, environmentally and socially sustainable NTFP-based businesses in the Russian Far East. One exciting development from the tour was the establishment of numerous marketing contacts with Canadian businesses interested in project products. Several fair-trade organizations as well as stores specializing in Native crafts placed orders for products, and many expressed interest in establishing long-term arrangements to market NTFPs from the Russian Far East.

Apart from the direct business benefits, the tour had other positive impacts within Canada that should not be overlooked. One of the highlights for Canadian participants in the Tour were presentations on birch bark weaving given by Nikolay Shishkin, the Native weaver from Kamchatka. Nikolay gave two presentations in Indigenous peoples' communities in Manitoba and conducted a short workshop for a group of basket weavers in Duncan, BC. All who participated were impressed with Nikolay's artistic talent and skill as a trainer and intrigued by the potential to "import" some of these skills to benefit craftspeople in Canada. His demonstrations created such an impression that Nikolay has been invited to lead two workshops on birch bark weaving in Canada next summer. Finally, the communities visited by the study tour will remember these visits for a long time. As one of the Elders of the community of Cormorant in Manitoba put it, "This visit is one of the most exciting events for our people for many, many years."

\section{Looking Ahead}

In less than two years, the project has overcome substantial roadblocks and demonstrated some significant achievements. The project still has many barriers to overcome before we reach our goal of establishing a self-sustaining NTFP industry that provides significant benefits to local communities. In the next three years, we hope to consolidate the gains the project has made, and create a steady flow of sustainably harvested NTFPs into national and international markets. We also hope to begin addressing some of the many barriers to success that new NTFP entrepreneurs - especially those without access to capital-face in developing their businesses. For example, for products to be legally sold in Russia, they must have government certification, a daunting and costly process for those with little or no business experience. The project hopes to address this challenge through the creation of a "certificate bank" where qualifying businesses (meeting criteria such as sustainability, benefits to local communities, and others) will be able to obtain proper certification for their products at a reduced cost. We will also continue the development of the educational program through the publication of booklets on traditional knowledge, and through support to cultural camps where young people can learn the traditional ways of the Indigenous people of Kamchatka. Another key task will be to share the lessons we have learned in the project thus far, in order that other projects with similar goals can benefit from both the successes and failures we have experienced.

Now that the project is moving from its "preparatory" stage to the point where local communities are receiving orders for NTFPs, people's interest in the potential of NTFPs and the activities of the project is growing. This interest and enthusiasm was clearly demonstrated by the success of the birch bark weaving workshop led by Nikolay Shishkin, a master of traditional weaving techniques using sustainably harvested bark. The workshop attracted tremendous interest with participants coming from all over the Kamchatka peninsula. In the few months since the workshop was held, those who attended have begun teaching weaving to others in their home villages. The art of weaving had disappeared from the communities of Bystrinski District, but the memory of this skill was still alive. As one of the Esso community leaders said, there was "something about the genes"he was surprised that he learned the craft with relative ease. $\mathrm{He}$ remembered different household items made from birch bark in his traditional homestead when he was a boy. In the 1960s, Native people were removed from their villages to larger settlements and most of their spiritual connections to nature and their traditional practices stopped. The project is providing an opportunity for people to re-learn the skills of their parents and grandparents, and, if they choose, to apply these "old" skills to the modern challenge of fashioning a livelihood in $21^{\text {st }}$-century Russia. Just as we are assisting local people to learn about the potential pitfalls and the promise of NTFP-based business development, our experiences in Bystrinski District have taught us new ways to better help communities in their quest for sustainable and equitable development.

\section{Acknowledgements}

The authors wish to thank Dr. Emma Wilson, Community Development Expert, Great Britain, a colleague on the project who shared many of our travels in the Russian Far East and whose experience and previous research opened many doors for us on Kamchatka and Sakhalin; Ms. Olga Davidova, legal expert, Petropavlovsk-Kamchatski, our good friend and keen partner; Ms. Danielle Cantin, TBFP IUCN-Canada, who played a key role in the development and implementation of the project; Roxanne Comeau, Canadian Institute of Forestry, without whose help this paper would never have happened; and our patient families, who miss us when we travel far from home. 